\title{
IMPROVING SOCIAL COMMUNICATION SKILLS IN AUTISM SPECTRUM DISORDERS USING PROGRAMMABLE TOY ROBOTS
}

\author{
Gilberto Marzano \\ Rezekne Academy of Technologies, Latvia \\ Academy of Social Sciences of Lodz, Poland \\ Valeria Tambato \\ Ecoististuto del Friuli Venezia Giulia \\ Azienda Sanitaria Universitaria Friuli Centrale, Italy \\ Simone Zorzi \\ Ecoististuto del Friuli Venezia Giulia \\ Azienda Sanitaria Universitaria Friuli Centrale, Italy
}

\begin{abstract}
Autism spectrum disorders (ASD) are a group of lifelong disabilities that affect people's ability to communicate and understand social cues. An individual with ASD has difficulties in recognizing body language, making eye contact, and understanding other people's emotions.

Rapid progress in technology offers increasing possibilities for innovation in treatment for individuals with ASD.

In recent years, advances have enabled programmable toy robots (PTRs) to help individuals improve their social skills and communication abilities. Over the past decade, the use of PTRs with autistic children has received considerable attention, even though research on this topic is in its infancy.

This article analyzes the recent progress in the use of PTRs in the ASD scope. It illustrates an exploratory research conducted on four adolescents with ASD aimed at defining an experiment to evaluate the effectiveness of PTRs in their social communication.

The exploratory research results are encouraging, although they demonstrated the complexity in determining the feasibility and validity of robots in the social communication of autistic people.
\end{abstract}

Keywords: Autism Spectrum Disorder, Programmable toy robots for autistic children, Robot therapy, Social communication of autistic children, Social robotics.

\section{Background}

Over the last two decades, digital technology has become increasingly popular in education. Nowadays, course management systems and e-learning platforms provide learners with tools and resources to support and enhance education management and delivery. 
Robotics is a growing field in which digital technology has found new forms of educational and therapeutic interventions. In this regard, robot therapy is a new application of robots that refers to the use of robotic devices as therapeutic tools (Agah, Cabibihan, Howard, Salichs, \& He, 2016; Tlili, Lin, Chen, \& Huang 2020). Robot therapy is attracting the attention of many researchers, and encompasses a broad range of robot-interactive treatments, from physical rehabilitation, such as for stroke and limb rehabilitation (Everard, Ajana, Dehem, Stoquart, Edwards, \& Lejeune, 2020; Ferreira, Chaves, Oliveira, Van Petten, \& Vimieiro, 2018) to cognitive or social applications, such as mental healthcare for the elderly, and for dementia and autism (Cruz-Sandoval, Morales-Tellez, Sandoval, \& Favela, 2020; Shibata \& Wada, 2011).

PARO is one example of a zoomorphic therapeutic robot primarily realized in order to study interactions with older adults with varying cognitive impairment levels. It showed a positive effect on users' emotional states and stress levels (Pu, Moyle, \& Jones, 2020; Šabanović, Bennett, Chang, \& Huber, 2013).

In the early 2010s, many studies were conducted with the aim of investigating the use of robots to support children's' cognition, language, interaction, and socialization (Toh, Causo, Tzuo, Chen, \& Yeo, 2016). From the results of these studies, various educational robots have been developed, such as the products from Waveshare or the Moxie robot designed by Embodied, to promote cognitive, emotional, and social learning (Hurst, Clabaugh, Baynes, Cohn, Mitroff, \& Scherer, 2020). These robots have different appearances, structures (hardware), systems (software), and functions (behavioral outcomes), and can be categorized as robotics kits, social robots, and toy robots (Jung \& Won, 2018). Robotics kits are programmable construction kits that can be used in roleplay activities (Janka, 2008). Social robots are increasingly used in an educational context since they are perceived as motivating, enjoyable, and engaging by the pupils, particularly in primary schools (Konijn, Smakman, \& van den Berghe, 2020). They interact with humans in a socially acceptable manner, aiming to increase the socialization and social communication capacities of users. They require deep models of social cognition, but can be used to support a wide range of social applications in contexts ranging from offices and hotels, to marketing, cooking, entertainment, hobbies, and recreation, as well as in health and nursing care, therapy, and rehabilitation (Dautenhahn, 2002; Lohse, Hegel, Swadzba, Rohlfing, Wachsmuth, \& Wrede, 2007; Dou, Wu, Wang, \& Niu, 2020). In contrast, toy robots are ready-made commercial robots intended for entertainment and play (Fernaeus, Håkansson, Jacobsson, \& Ljungblad, 2010). Commercial programmable toy robots are designed to be programmed by kids using a simplified drag-and-drop software interface on their computer, such as Lego Boost, Robotkity, Plobot, Kamibot, Awesome Shield, Scratch and ScratchJr, mTiny Genius Kit, Sphero, and so on. Using these programs, kids exercise their 
problem-solving skills and creativity, exploring and experimenting with new solutions.

In recent years, programmable toy robots (PTRs) have been experimented in the scope of helping individuals improve their social skills and communication abilities. Over the past decade, the use of PTRs with autistic children has received considerable attention, even though research on this topic is still in its infancy (Begum, Serna, \& Yanco, 2016; Cabibihan, Javed, Ang, \& Aljunied, 2013; Saleh, Hashim, Mohamed, Abd Almisreb, \& Durakovic, 2020).

Some humanoid robots such as Zeno R-50, Nao and Kaspar, as well as nonhumanoid robots such as Pleo, Keepon, and Popchilla, have been experimented as vehicles for promoting the social skills of children with autism (Dickstein-Fischer, Crone-Todd, Chapman, Fathima, \& Fischer, 2018; Gandomi, 2018). Milo by RoboKind (Figure 1) is one of the most advanced robots designed to support social and emotional learning for people with ASD (https://robots4autism.com/milo/). Working with Milo, individuals with ASD learn to:

- $\quad$ Tune in on emotions

- $\quad$ Express empathy

- Act more appropriately in social situations

- $\quad$ Self-motivate

- Generalize in the population

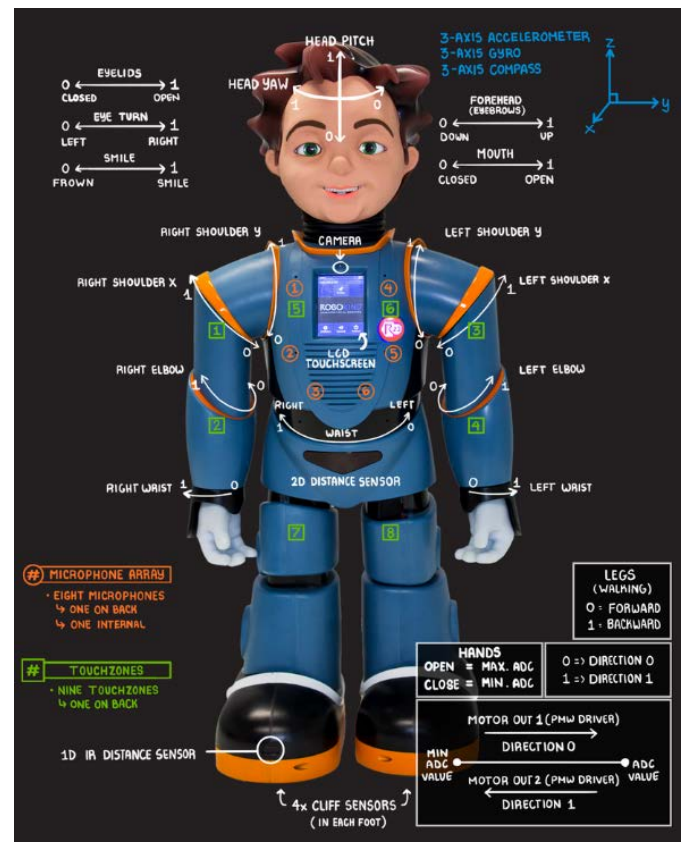

Figure 1 Specifications of Milo Robot (source: https://robots4autism.com/milo/) 
Marzano et al., 2021. Improving Social Communication Skills in Autism Spectrum Disorders Using Programmable Toy Robots

This article illustrates an exploratory research conducted on four young adults with ASD aimed at defining an experiment to evaluate the use of low-cost commercial PTRs in their social communication. The research has also been suggested by the need to design remote educational interventions for people with ASD. Indeed, due to the COVID-19 outbreak, social services have been forced to find new forms of interventions, moving from face-to-face to remote support of their users.

\section{Research Objective and Methodology}

This research is the first step of a larger investigation process whose objective is to define an integrated project aimed at developing PTR-based solutions for children and adolescents with ASD. The expected project results are:

Design and implementation of a low-cost PTR that social educators can use in schools and social services to encourage the communication and socialemotional abilities of children and adolescents with ASD;

Design educational guidance for social educators to develop PTR-based programs for children and adolescents with ASD.

The project envisages three main phases:

Phase I. Preparatory investigation. This concerns the review of scientific literature on PTRs, the collection and analysis of experiences, and the definition and carrying out of experiments to guide the further phases.

Phase II. Implementation. This concerns the design and realization of a lowcost PTR, and the definition of guidelines and examples for social educators to follow in order to develop educational programs for children and adolescents with ASD based on PTRs.

Phase III. Refinement. This concerns the analysis and evaluation of the Implementation phase. An educational module for social educators on the use of PTRs will be realized and tested. The final version of Guidelines and Exercises will be released. A Handbook will be published.

This article reports on an exploratory study carried out within phase I of the project that was aimed at defining the boundaries for the use of low-cost commercial PTRs to improve social communication skills in ASD. It includes a preliminary literature review and an on-field experience conducted in collaboration with the Social Health Disability Services of the Friuli Venezia Giulia Region.

The literature review analyzed over 70 articles published over the last two decades that are available in various in databases (Scopus, Web of Science, SAGE, ERIC, IEEE, etc.), following a consolidated methodology (Booth, Sutton, \& Papaioannou, 2016; Fink, 2019; Jesson, Matheson, \& Lacey, 2011). To collect relevant and significant publications, authors used keywords such as 
"robot therapy”, “social robots”, "social robotics”, “autism robots”, "socialization of robotics", "robotics education", etc. Part of the analysis has been used to provide this article with an overview of autism and social robotics. The authors are aware that further literature following the basic idea of robotics for ASD does exist. However, due to the limited time available for the literature analysis (JulyDecember 2020), a restricted number of articles was considered. Systematic reviews have been privileged.

The in-field experience for the use of PTRs to support social communication skills in ASD was garnered at the Day Care Center for ASD operated by the Social Health Disability Services of the Friuli Venezia Giulia Region. It involved four adolescents with a severe level of ASD, the director of the service, and an educator. Neither the director nor the educator were skilled in robotics, and were using a PTR for the first time. Nevertheless, they were very familiar with the involved adolescents and their status. The activity took place in the occupational room of the daycare service using Lego Boost robots. Lego Boost is a kit developed by Lego Education that allows children aged 8-12 years to learn about engineering, technology, programming, and robotics. It comprises 847 Lego bricks with which to assemble 5 different robots (Vernie the robot, Frankie the cat, the MTR4, the Autobuilder, and the Guitar), and includes an interactive engine, color, tilt, and distance sensors, and the Boost Hub to connect the robot to a tablet or smartphone. The authors used the Vernie robot (Figure 2). The use of Lego Boost in relation to ASD is shared by other researchers (Barakova, Bajracharya, Willemsen, Lourens, \& Huskens, 2015; Huskens, Palmen, Van der Werff, Lourens, \& Barakova, 2015; Levy \& Dunsmuir, 2020). The overriding aim is to find an effective translation of LEGO therapy (LeGoff, 2004; LeGoff \& Sherman, 2006; Owens, Granader, Humphrey, \& Baron-Cohen, 2008) to playful robot-mediated training.

The field experience was conducted in three steps:

- $\quad$ The educator built two Vernie robots together with one of the autistic adolescents involved in the in-field activity, then studied and tested their functions using Lego Boost manuals and online videos (Benedettelli, 2018; Bundschuh, 2019).

- $\quad$ The four autistic adolescents played with Vernie under the supervision of the educator.

- $\quad$ The educator programmed Vernie for simple social communication interactions. The four autistic adolescents, separately, communicated with the robot, e.g., saying "hello", saying "goodbye”, saying "thanks", instructing Vernie how to move to achieve a goal, etc. An external observer filmed their activity (Figure 3). 
Marzano et al., 2021. Improving Social Communication Skills in Autism Spectrum Disorders Using Programmable Toy Robots

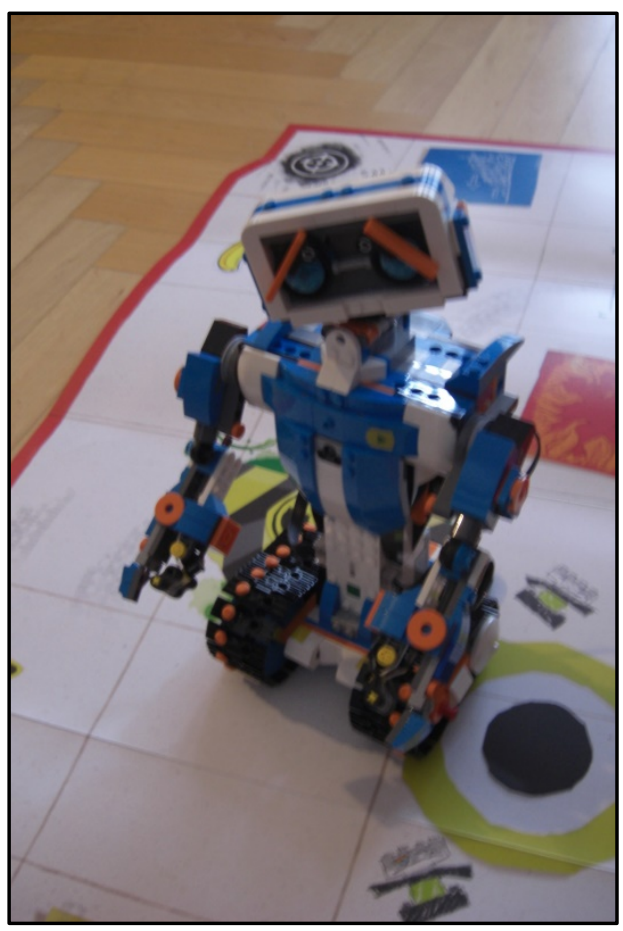

Figure 2 The Lego Boost Vernie robot (own source);

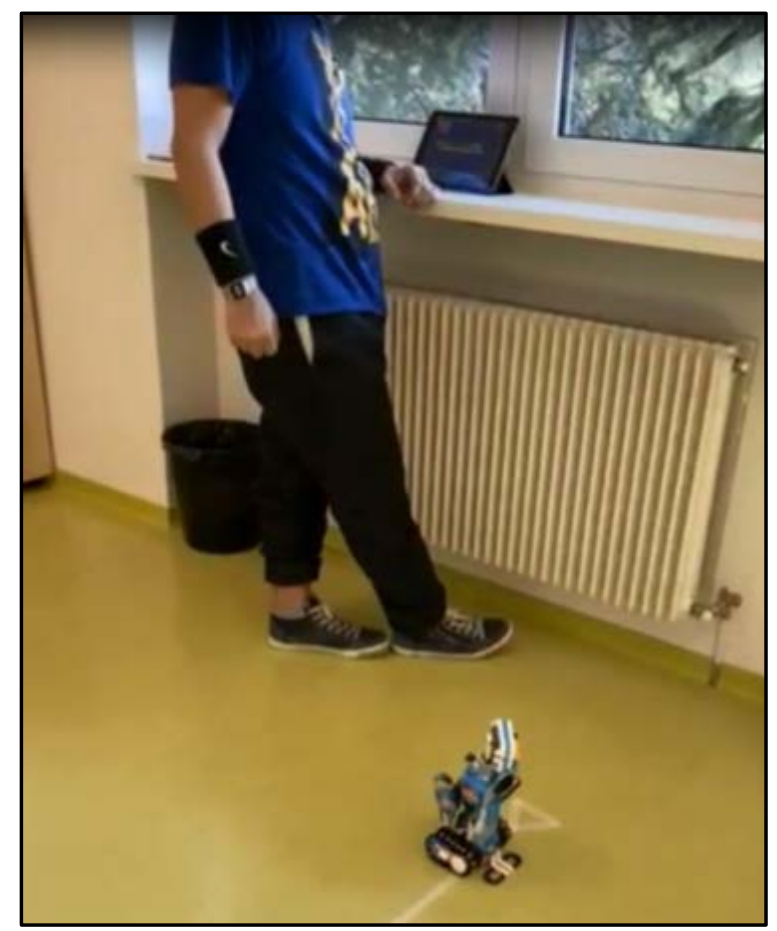

Figure 3 An Autistic Adolescent Interacting with Vernie (own source)

Videos have been analyzed considering two behavioral dimensions of the engaged autistic adolescents:

Verbal behavior in interacting with Vernie and answering the questions posed by the educator, such as "what is Vernie doing?", "how must Vernie move to get a given goal?”, etc.

Social behavior in collaborating with the educator in programming and carrying out the Vernie tasks.

\section{Findings}

The in-field experience confirmed that PTRs represent a powerful means for engaging with children and adolescents with ASD, as well as for improving their social communication skills (Kostrubiec \& Kruck, 2020; Ricks \& Colton, 2010; Talaei-Khoei, Lewis, Kaul, Daniel, \& Sharma, 2017).

All the autistic adolescents involved in the in-field experience showed empathy towards Vernie, interacting with it as a pair. They were enthusiastic about the activity, not bored to repeat a task, and were strongly engaged in communicating with the robot. The interaction with Vernie stimulated their creativity. They were excited to describe their relationship with Vernie to the educator, readily transferred their feelings to the robot, and also attempted to offer it suggestions and advice. 
However, the limitations of the in-field experience evidenced two crucial elements that can be considered as its main results.

The first concerns the competence of educators involved in social robotics. It is necessary to define a competency framework that includes knowledge in computing and basic robotics, and competence in rehabilitation for psychocognitive and behavioral disturbances, special needs education, social communication, and socialization of individuals with special needs.

The second regards the definition of specific educational and rehabilitation strategies and the demonstration of their effectiveness. The use of PTRs should be contextualized and appropriate social communication situations should be designed, according to the robots' available functions.

The authors' opinion is that the storytelling method could be used to create social communication situations, as well as for sharing and interpreting social experiences (Fog, Budtz, \& Yakaboylu, 2005; Herman, 2013; Sephvandi \& Sahebalzamani, 2019).

In this regard, it has been observed that the social performance of autistic children improves when using a robot as a medium for social storytelling (Attawibulkul, Sornsuwonrangsee, Jutharee, \& Kaewkamnerdpong, 2019; Vanderborght et al., 2012). The in-field experience showed that the autistic adolescents interacted with Vernie, saying "hello", saying "thank you", and directing the robot how to move in order to achieve a given task.

Finally, different PRTs should be experimented to identify the functions that demonstrate the greatest effectiveness. Furthermore, using open source physical computer platforms is less expensive and gives educators the opportunity to master robotics, stimulating their creativity (Ziouzios, Ioannou, Ioanna, Bratitsis, \& Dasygenis, 2020). Arduino (https://www.arduino.cc) and Raspberry Pi (https://www.raspberrypi.org/) are, currently, the most well-known technology for hobbyists and education. They can offer low-cost tools for prototyping and experimentation.

\section{Further Developments}

This research is the first step of a larger investigation process whose ultimate objective is to define an integrated project aimed at developing social robotics interventions. The next steps are related to the completion of phase I, specifically:

- $\quad$ Defining the competency framework for social robotics.

- $\quad$ Organizing a training course for educators in social robotics.

- $\quad$ Realizing a pilot experiment involving children with ASD. 
Marzano et al., 2021. Improving Social Communication Skills in Autism Spectrum Disorders Using Programmable Toy Robots

- Creating an interdisciplinary laboratory involving psychiatrists, psychotherapists, cognitive scientists, roboticists, computer scientists, and special needs education experts.

A pilot experiment will be designed involving children with ASD and skilled educators, and combine social storytelling with PTRs. It will differ from storytelling with robots in which children teach a robot to tell stories (Chen \& Wang, 2011). Instead, in the pilot experiment, the robot will be used to represent a story.

Two types of social storytelling will be adopted. Social situational storytelling (SSS) and creative social storytelling (CSS).

Examples of SSS are:

1. Going to a supermarket to buy a box of cookies (actions: enter the supermarket, find the box of cookies, go to the cash register, say hello to the cashier, pay, say goodbye to the cashier, exit the supermarket).

2. Walking to a place, e.g., a public garden or a library (actions: plan the walking, say hello to people met along the route, recognize objects, such as a fountain, trees, buildings, give advice to the robot on crossing roads, etc.).

In CSS, the educator and the autistic child co-create a story that allows reallife to be reflected in a set of structured social experiences (Conn, 2019; GalloLopez \& Rubin, 2012). These stories can get inspiration from a picture, a character from a book or movie, or a real person. Under the educator's guidance, the autistic child should identify the task to be executed by the robot whilst the educator should program the robot to execute them. The child should sustain the robot by giving it suggestions, advice, and reinforcement.

The pilot experiment is the necessary step for therapeutic intervention. It should be repeated with a large number of subjects and refined. The advantage is the creation of a library of stereotyped situations that can be updated with new experiences. This library could be the initial knowledge base on autism stereotyped behavior.

\section{Conclusion}

ASD presents a multitude of behavioral deficiencies that might manifest in inflexible behavior and difficulties in socially interacting, communicating, and expressing empathy.

The application of robots in ASD has received considerable attention over the past two decades (Cao et al., 2019; Fachantidis, Syriopoulou-Delli, \& Zygopoulou, 2020). Robots provide predictable and repetitive interactions, and increase engagement and attention, while decreasing social anxiety in individuals with ASD. Moreover, social robots can be used in the remote education of 
children with ASD and, in fact, the current COVID-19 pandemic has fostered the development of experiments for this purpose.

Currently, research into the application of robots in ASD appears fragmented since it focuses on many different aspects and dimensions (Ferrão, Romero, Ramos, \& Azevedo, 2020).

The present exploratory study shows that it is necessary to invest in autism stereotyped behavior and the definition of structured interaction experiments.

A methodological effort should be made to aggregate the various research scopes. Moreover, a competency framework for social robotics should be developed, while training courses should be experimented that draw contributions from different disciplines.

Despite the limits of this present study, however, the results encourage the research to continue further and tackle the challenges of the follow-on steps.

\section{References}

Agah, A., Cabibihan, J.J., Howard, A.M., Salichs, M.A., \& He, H. (Eds.) (2016). Social Robotics: ${ }^{\text {th }}$ International Conference, ICSR 2016, Kansas City, MO, USA, November 13, 2016 Proceedings. Springer, Vol. 9979.

Attawibulkul, S., Sornsuwonrangsee, N., Jutharee, W., \& Kaewkamnerdpong, B. (2019). Using Storytelling Robot for Supporting Autistic Children in Theory of Mind. International Journal of Bioscience, Biochemistry and Bioinformatics, 9(2), 100-108.

Barakova, E.I., Bajracharya, P., Willemsen, M., Lourens, T., \& Huskens, B. (2015). Long-term LEGO therapy with humanoid robot for children with ASD. Expert Systems, 32(6), 698-709.

Begum, M., Serna, R.W., \& Yanco, H.A. (2016). Are robots ready to deliver autism interventions? A comprehensive review. International Journal of Social Robotics, 8(2), 157-181.

Benedettelli, D. (2018). The Lego Boost Activity Book: A Beginner's Guide to Robotics, No Starch Pr.

Booth, A., Sutton, A., \& Papaioannou, D. (2016). Systematic approaches to a successful literature review. Sage.

Bundschuh, B. (2019). The LEGO BOOST Expert Book: Building and Programming Instructions for 6 additional models based on the Boost-Set, Independently published.

Cabibihan, J.J., Javed, H., Ang, M., \& Aljunied, S.M. (2013). Why robots? A survey on the roles and benefits of social robots in the therapy of children with autism. International journal of social robotics, 5(4), 593-618.

Cao, H.L., Esteban, P.G., Bartlett, M., Baxter, P., Belpaeme, T., Billing, E., ... \& Ziemke, T. (2019). Robot-enhanced therapy: development and validation of supervised autonomous robotic system for Autism Spectrum Disorders Therapy. IEEE robotics \& automation magazine, 26(2), 49-58.

Chen, G.D. \& Wang, C.Y. (2011). A survey on storytelling with robots. International Conference on Technologies for E-Learning and Digital Entertainment, 450-456. 
Marzano et al., 2021. Improving Social Communication Skills in Autism Spectrum Disorders Using Programmable Toy Robots

Conn, C. (2019). Using Drama with Children on the Autism Spectrum: A Resource for Practitioners in Education and Health. Routledge.

Cruz-Sandoval, D., Morales-Tellez, A., Sandoval, E.B., \& Favela, J. (2020). A Social Robot as Therapy Facilitator in Interventions to Deal with Dementia-related Behavioral Symptoms. Proceedings of the 2020 ACM/IEEE International Conference on Human-Robot Interaction, 161-169.

Dautenhahn, K. (2002). Design spaces and niche spaces of believable social robots. In Proceedings. $11^{\text {th }}$ IEEE International Workshop on Robot and Human Interactive Communication, 192-197.

Dickstein-Fischer, L.A., Crone-Todd, D.E., Chapman, I.M., Fathima, A.T., \& Fischer, G.S. (2018). Socially assistive robots: current status and future prospects for autism interventions. Innovation and Entrepreneurship in Health, 5, 15-25.

Dou, X., Wu, C.F., Wang, X., \& Niu, J. (2020). User Expectations of Social Robots in Different Applications: An Online User Study. International Conference on Human-Computer Interaction, 64-72.

Everard, G.J., Ajana, K., Dehem, S.B., Stoquart, G.G., Edwards, M.G., \& Lejeune, T.M. (2020). Is cognition considered in post-stroke upper limb robot-assisted therapy trials? A brief systematic review. International Journal of Rehabilitation Research, 43(3), 195-198.

Fachantidis, N., Syriopoulou-Delli, C.K., \& Zygopoulou, M. (2020). The effectiveness of socially assistive robotics in children with autism spectrum disorder. International Journal of Developmental Disabilities, 66(2), 113-121.

Fernaeus, Y., Håkansson, M., Jacobsson, M., \& Ljungblad, S. (2010). How do you play with a robotic toy animal? A long-term study of Pleo. Proceedings of the $9^{\text {th }}$ international Conference on interaction Design and Children, 39-48.

Ferrão, I.G., Romero, R.A., Ramos, J., \& Azevedo, H. (2020). Robotic assistance for autism: a literature review. November 2020 Latin American Robotics Symposium (LARS), 2020 Brazilian Symposium on Robotics (SBR) and 2020 Workshop on Robotics in Education (WRE) (1-6). IEEE.

Ferreira, F.M.R.M., Chaves, M.E.A., Oliveira, V.C., Van Petten, A.M.V.N., \& Vimieiro, C.B.S. (2018). Effectiveness of robot therapy on body function and structure in people with limited upper limb function: A systematic review and meta-analysis. PloS one, 13(7), e0200330.

Fink, A. (2019). Conducting research literature reviews: From the internet to paper, Sage.

Fog, K., Budtz, C., \& Yakaboylu, B. (2005). Storytelling. Berlin: Springer.

Gallo-Lopez, L. \& Rubin, L.C. (Eds.) (2012). Play-based interventions for children and adolescents with autism spectrum disorders. Routledge.

Gandomi, F. (2018). Analysis and Prediction of Emotions using Human-Robot and DriverVehicle Interactions, Doctoral dissertation, Northeastern University Boston. Retrieved from: https://repository.library.northeastern.edu/files/neu:cj82sr87z/fulltext.pdf

Herman, D. (2013). Storytelling and the Sciences of Mind. MIT press.

Hurst, N., Clabaugh, C., Baynes, R., Cohn, J., Mitroff, D., \& Scherer, S. (2020). Social and Emotional Skills Training with Embodied Moxie. arXiv preprint arXiv:2004.12962. Retrieved from: https://arxiv.org/pdf/2004.12962.pdf

Huskens, B., Palmen, A., Van der Werff, M., Lourens, T., \& Barakova, E. (2015). Improving collaborative play between children with autism spectrum disorders and their siblings: The effectiveness of a robot-mediated intervention based on Lego ${ }^{\circledR}$ therapy. Journal of autism and developmental disorders, 45(11), 3746-3755. 
Konijn, E.A., Smakman, M., \& van den Berghe, R. (2020). Use of robots in education. The International Encyclopedia of Media Psychology, 1-8.

Kostrubiec, V. \& Kruck, J. (2020). Collaborative research project: developing and testing a robot-assisted intervention for children with autism. Frontiers in Robotics and AI, 7, 37.

Janka, P. (2008). Using a programmable toy at preschool age: Why and how. Teaching with robotics: didactic approaches and experiences. Workshop of International Conference on Simulation, Modeling and Programming Autonomous Robots, 112-121.

Jesson, J., Matheson, L., \& Lacey, F.M. (2011). Doing your literature review: Traditional and systematic techniques. Sage.

Jung, S.E. \& Won, E.S. (2018). Systematic review of research trends in robotics education for young children. Sustainability, 10(4), 905. Retrieved from: https://www.mdpi.com/20711050/10/4/905/htm

LeGoff, D.B. (2004). Use of LEGOC as a therapeutic medium for improving social competence. Journal of autism and developmental disorders, 34(5), 557-571.

LeGoff, D.B. \& Sherman, M. (2006). Long-term outcome of social skills intervention based on interactive LEGO@ play. Autism, 10(4), 317-329.

Levy, J. \& Dunsmuir, S. (2020). Lego therapy: Building social skills for adolescents with an autism spectrum disorder. Educational and Child Psychology, 37(1), 58-83.

Lohse, M., Hegel, F., Swadzba, A., Rohlfing, K., Wachsmuth, S., \& Wrede, B. (2007). What can I do for you? Appearance and application of robots. Proceedings of AISB, Vol. 7, 121-126.

Owens, G., Granader, Y., Humphrey, A., \& Baron-Cohen, S. (2008). LEGO® therapy and the social use of language programme: An evaluation of two social skills interventions for children with high functioning autism and Asperger syndrome. Journal of autism and developmental disorders, 38(10), 1944-1957.

Ricks, D.J. \& Colton, M.B. (2010). Trends and considerations in robot-assisted autism therapy. 2010 IEEE international conference on robotics and automation, 4354-4359.

Šabanović, S., Bennett, C.C., Chang, W.L., \& Huber, L. (2013). PARO robot affects diverse interaction modalities in group sensory therapy for older adults with dementia. 2013 IEEE $13^{\text {th }}$ international conference on rehabilitation robotics (ICORR), 1-6.

Saleh, M.A., Hashim, H., Mohamed, N.N., Abd Almisreb, A., \& Durakovic, B. (2020). Robots and autistic children: a review. Periodicals of Engineering and Natural Sciences (PEN), 8(3), 1247-1262.

Shibata, T. \& Wada, K. (2011). Robot therapy: a new approach for mental healthcare of the elderly-a mini-review. Gerontology, 57(4), 378-386.

Pu, L., Moyle, W., \& Jones, C. (2020). How people with dementia perceive a therapeutic robot called PARO in relation to their pain and mood: A qualitative study. Journal of Clinical Nursing, 29(3-4), 437-446.

Sephvandi, S. \& Sahebalzamani, M. (2019). Investigating the Effect of Storytelling on Role Playing Method on Sensory-Cognitive and Interpersonal Knowledge in Children with Autism Spectrum Disorder. Jundishapur Scientific Medical Journal, 17(6), 621-630.

Talaei-Khoei, A., Lewis, L., Kaul, M., Daniel, J., \& Sharma, R. (2017). Use of lean robotic communication to improve social response of children with autism. AMCIS 2017America's Conference on Information Systems: A Tradition of Innovation.

Tlili, A., Lin, V., Chen, N.S., \& Huang, R. (2020). A Systematic Review on Robot-Assisted Special Education from the Activity Theory Perspective. Educational Technology \& Society, 23(3), 95-109. 
Marzano et al., 2021. Improving Social Communication Skills in Autism Spectrum Disorders Using Programmable Toy Robots

Toh, L.P.E., Causo, A., Tzuo, P.W., Chen, I.M., \& Yeo, S.H. (2016). A Review on the Use of Robots in Education and Young Children. Educational Technology \& Society, 19 (2), 148-163.

Vanderborght, B., Simut, R., Saldien, J., Pop, C., Rusu, A.S., Pintea, S., ... \& David, D.O. (2012). Using the social robot probo as a social story telling agent for children with ASD. Interaction Studies, 13(3), 348-372.

Ziouzios, D., Ioannou, M., Ioanna, T., Bratitsis, T., \& Dasygenis, M. (2020). Emotional Intelligence and Educational Robotics: The Development of the EIEDUROBOT. European Journal of Engineering Research and Science. Retrieved from: https://www.ejers.org/index.php/ejers/article/view/2307 